Ciência Florestal, Santa Maria, v. 21, n. 1, p. 17-22, jan.-mar., 2011

ISSN 0103-9954

\title{
BIOMASSA EM POVOAMENTOS DE Eucalyptus spp. DE PEQUENAS PROPRIEDADES RURAIS EM VERA CRUZ, RS
}

\author{
BIOMASS IN Eucalyptus spp. STANDS IN SMALL RURAL PROPERTIES IN VERA CRUZ, RS
}

\author{
Mauro Valdir Schumacher ${ }^{1}$ Rudi Witschoreck ${ }^{2}$ Francine Neves Calil ${ }^{3}$
}

RESUMO

O estudo foi realizado em povoamentos de Eucalyptus spp. de 2, 4, 6 e 8 anos de idade, no município de Vera Cruz, no estado do Rio Grande do Sul. A amostragem da biomassa de eucalipto consistiu no abate de 24 árvores, seis árvores por idade, distribuídas em três classes diamétricas. Também foram amostrados os compartimentos: sub-bosque e serapilheira. Foi estimada uma biomassa de 26,70; 44,55; 192,67 e 232,93 $\mathrm{Mg} \mathrm{ha}^{-1}$ no eucalipto; 1,$87 ; 1,97 ; 4,37$ e $8,24 \mathrm{Mg} \mathrm{ha}^{-1}$ no sub-bosque e 4,05; 5,98; 11,80 e $12,28 \mathrm{Mg} \mathrm{ha}^{-1}$ na serapilheira, totalizando 32,$62 ; 52,50 ; 208,84$ e $253,45 \mathrm{Mg} \mathrm{ha}^{-1}$, respectivamente, no povoamento de 2 , 4, 6 e 8 anos de idade. Com exceção da madeira do tronco todos os demais componentes das árvores de eucalipto apresentaram redução da biomassa relativa com o aumento da idade do povoamento.

Palavras-chave: Eucalyptus; silvicultura; recursos bioenergéticos; produtividade florestal.

\begin{abstract}
The study was conducted in 2, 4, 6 and 8 year-old Eucalyptus spp. stands, in the municipality of Vera Cruz, RS. The eucalyptus biomass sampling consisted of felling 24 trees, 6 trees per age, distributed in three diametric classes. The understory and litter compartments were also sampled. The estimated biomass was $26.70 ; 44.55 ; 192.67$ and $232.93 \mathrm{Mg} \mathrm{ha}^{-1}$ in eucalypt; $1.87 ; 1.97 ; 4.37$ and $8.24 \mathrm{Mg}^{-1}$ in understory and 4,$05 ; 5,98 ; 11,80$ and $12,28 \mathrm{Mg} \mathrm{ha}^{-1}$ in the litter, totaling $32.62 ; 52.50 ; 208.84$ and $253.45 \mathrm{Mg} \mathrm{ha}^{-1}$, respectively, in 2, 4, 6 and 8 year stands. Except for the wood, all the other components of eucalypt trees showed a decrease in relative biomass with the increase of age.
\end{abstract}

Keywords: Eucalyptus; silviculture; bioenergy resources; forest production.

\section{INTRODUÇÃO}

O eucalipto é a essência mais utilizada em plantios florestais no Brasil, sendo que, em 2008, dos 6.583.074 ha de área total, 4.258.704 ha ou $64,7 \%$ eram ocupados com espécies desse gênero, dos quais, 277.316 ha ou $7,4 \%$ pertencem ao Rio Grande do Sul (ABRAF, 2009).

A elevada utilização do eucalipto nos florestamentos brasileiros é favorecida pela boa adaptação da árvore, nas suas diferentes espécies, às condições de clima e solo. $\mathrm{O}$ aumento da produtividade foi alavancado pelo melhoramento genético tradicional e pela clonagem (MCT, 2005).

As espécies do gênero Eucalyptus apresentam elevada eficiência nutricional em razão de sua maior capacidade de retranslocação de nutrientes em relação a outras espécies florestais, especialmente coníferas (ATTIWILL, 1980; CRANE e RAISON, 1980; REIS e BARROS, 1990). Além dessa característica, a capacidade de adaptação a situações de déficit hídrico apresentadas por algumas espécies desse gênero tem permitido que os plantios sejam implantados na região dos cerrados, onde os solos, em sua maioria, apresentam baixa fertilidade, associado a clima onde é observado um pronunciado déficit hídrico numa estação do ano. Porém, a produtividade dessas florestas pode ser consideravelmente aumentada com a adubação (BALLARD, 1984; BALLONI,

1. Engenheiro Florestal, Dr., Professor do Departamento de Ciências Florestais da Universidade Federal de Santa Maria, Av. Roraima, 1000, CEP 97105-900, Santa Maria (RS). Bolsista do CNPq. schumacher@pq.cnpq.br

2. Engenheiro Florestal, Doutorando do Programa de Pós-Graduação em Engenharia Florestal, Universidade Federal de Santa Maria, Av. Roraima, 1000, CEP 97105-900, Santa Maria (RS).rwitschoreck@yahoo.com.br

3. Engenheira Florestal, Drạ., Professora da Escola de Agronomia e Engenharia de Alimentos da Universidade Federal de Goiás, Rodovia Goiânia, Nova Veneza, km 0, Campus Samambaia, CEP 74690-900, Goiânia (GO). francine.calil@terra.com.br

Recebido para publicação em 16/04/2009 e aceito em 18/05/2010. 
1984; BARROS et al., 1990; NOVAIS et al., 1990) e com a adoção de espaçamentos que permitem o uso adequado dos nutrientes, da água e da radiação solar (REIS e REIS, 1993; GOMES, 1994; BERNARDO, 1995).

O desenvolvimento rural sustentável implica no planejamento adequado do processo de produção agrícola e florestal, identificando e protegendo adequadamente as áreas de proteção para que se tenha água, biodiversidade e outros serviços ambientais, de forma a possibilitar o uso racional dos espaços produtivos da paisagem. No caso de plantações florestais, por exemplo, o setor evoluiu bastante nesse sentido, com a adoção de práticas sustentáveis de manejo florestal (REMADE, 2003).

$\mathrm{Na}$ área do presente estudo, os florestamentos com eucalipto apresentam vários aspectos positivos. Economicamente, as florestas proporcionam biomassa barata que viabiliza atividades que necessitam dessa fonte de energia. Ecologicamente, além de amenizar a pressão sobre os parcos remanescentes de florestas naturais, os plantios de eucalipto possibilitam uma melhor utilização da área das propriedades, permitindo a reintegração de áreas "marginais", mal-drenadas ou de topografia mais acidentada onde desempenha importante papel na preservação do solo e dos recursos hídricos.

Mais recentemente, as florestas de crescimento rápido, especialmente, como as de eucalipto, estão sendo indicadas como possíveis drenos do carbono atmosférico. Desde a revolução industrial, em decorrência da utilização de combustíveis fosseis e da destruição das florestas naturais, houve uma elevação de mais de $20 \%$ na concentração de dióxido de carbono $\left(\mathrm{CO}_{2}\right)$ na atmosfera (LAL et al., 1998). O efeito estufa é natural e necessário para a continuidade da vida na Terra, porém a intensificação desse fenômeno, causada por atividades humanas, está causando a mudança climática global (GUREVITCH et al., 2009). Como os vegetais têm a capacidade de fixar o carbono, os plantios de floresta têm se mostrado como uma opção para o "sequestro de carbono".

Este estudo teve como objetivo quantificar o acúmulo de biomassa em povoamentos de Eucalyptus spp. com diferentes idades (2, 4, 6 e 8 anos), segmentada nos compartimentos: eucalipto (subdividido nos componentes folha, galho vivo, galho morto, casca, madeira e raiz), sub-bosque (acima e abaixo do solo) e na serapilheira.

\section{MATERIAL E MÉTODO}

$\mathrm{O}$ estudo foi realizado em pequenas propriedades rurais no município de Vera Cruz, no estado do Rio Grande do Sul. Segundo Köppen, a área compreende o tipo climático $\mathrm{Cfa} 2$, que corresponde ao clima subtropical (MORENO, 1961). A precipitação pluviométrica da região fica em torno dos $1.650 \mathrm{~mm}$ anuais. Os solos têm como material de origem arenitos, siltitos e argilitos, predominando Argissolo Bruno-Acinzentado (STRECK et al., 2008).

$\mathrm{O}$ inventário florestal foi realizado em povoamentos de Eucalyptus spp. de 2, 4, 6 e 8 anos de idade, em áreas de primeiro corte, com levantamento de quatro parcelas de $12 \mathrm{~m}$ x $20 \mathrm{~m}$ em cada um dos povoamentos onde foram medidos todos os diâmetros das árvores à altura do peito (dap) e $20 \%$ das alturas totais.

Com base nos dados obtidos no inventário florestal, a amplitude diamétrica observada em cada povoamento foi separada em três classes de diâmetro (dap), sendo abatidas duas árvores com diâmetro médio em cada classe, totalizando seis árvores por povoamento. Após o abate de cada árvore, a biomassa foi dividida nos seguintes componentes: folha, galho vivo, galho morto, madeira, casca e raiz.

Paralelamente a determinação da biomassa de casca e madeira, foi realizada uma cubagem rigorosa do fuste. Para facilitar a pesagem e a obtenção das medidas de diâmetro com e sem casca, o fuste foi secionado nos pontos de cubagem. Cada seç̧ão do tronco foi pesada com e sem casca, para obtenção da biomassa de madeira e casca.

A biomassa de raiz foi determinada após escavação, manual e com retroescavadeira, do sistema radicular, até $1,8 \mathrm{~m}$ de profundidade e lavagem para a retirada do solo aderido.

Para determinação do teor de umidade, foi coletada uma amostra dos componentes: folha, galho vivo, galho morto e raiz; e três amostras de casca e madeira, nas seguintes posições ao longo do fuste: dap (1,30 m da base da árvore), a 50 e a $75 \%$ da altura total da árvore.

Neste estudo, foi considerado como subbosque todo tipo de vegetação, de ocorrência espontânea, seja nativa ou exótica. No centro de cada uma das parcelas do inventário florestal, foi demarcada uma parcela de $4 \mathrm{~m} \times 3 \mathrm{~m}$ onde foi coletada toda a biomassa acima e abaixo do solo, pesada e amostrada.

Ci. Fl., v. 21, n. 1, jan.-mar., 2011 
De serapilheira, foram coletadas dez amostras de $25 \mathrm{~cm} \times 25 \mathrm{~cm}$ em cada uma das parcelas do inventário florestal, totalizando quarenta amostras por povoamento.

Cada uma das amostras de biomassa coletada foi pesada em balança digital com precisão de $0,1 \mathrm{~g}$, identificada e armazenada em saco de papel.

No laboratório, as amostras de eucalipto, sub-bosque e serapilheira foram secas em estufa com circulação e renovação de ar à temperatura de $70^{\circ} \mathrm{C}$ até estabilização do peso. Após a secagem, as amostras foram pesadas em balança eletrônica com precisão de $0,01 \mathrm{~g}$, para a determinação da massa seca.

A estimativa da biomassa por hectare, de cada um dos componentes das árvores de eucalipto, foi realizada utilizando a biomassa média e o número de árvores por hectare e classe diamétrica em cada povoamento. No caso do sub-bosque e serapilheira, a estimativa foi possível mediante extrapolação da biomassa média em função da área amostral.

\section{RESULTADOS E DISCUSSÃO}

A Tabela 1 apresenta as características dos povoamentos estudados na qual se destaca a alta densidade com que é cultivado o eucalipto nas pequenas propriedades rurais, com uma área útil por planta, às vezes, inferior a $3 \mathrm{~m}^{2}$.

TABELA 1: Características dendrométricas dos povoamentos de Eucalyptus spp. em propriedades rurais de Vera Cruz, RS, 2003.

TABLE 1: Dendrometric characteristics of Eucalyptus spp. stands in rural properties in Vera Cruz, RS, 2003.

\begin{tabular}{|c|c|c|c|c|}
\hline \multirow{2}{*}{ Parâmetro } & \multicolumn{4}{|c|}{ Idade do povoamento (anos) } \\
\hline & 2 & 4 & 6 & 8 \\
\hline Dap $(\mathrm{cm})$ & 6,5 & 6,8 & 12,8 & $\overline{13,2}$ \\
\hline $\begin{array}{l}\text { Densidade } \\
\left(\text { árvores } \mathrm{ha}^{-1}\right)\end{array}$ & 2645,8 & 3569,4 & 2354,2 & 2375,0 \\
\hline $\begin{array}{l}\text { Altura dominante } \\
\text { (m) }\end{array}$ & 11,9 & 14,0 & 27,4 & 28,6 \\
\hline $\begin{array}{l}\text { Volume de madeira } \\
\text { com casca }\left(\mathrm{m}^{3} \mathrm{ha}^{-1}\right)\end{array}$ & 48,4 & 80,2 & 344,4 & 414,0 \\
\hline $\begin{array}{l}\text { Volume de madeira } \\
\text { sem casca }\left(\mathrm{m}^{3} \mathrm{ha}^{-1}\right)\end{array}$ & 36,5 & 62,9 & 307,2 & 370,6 \\
\hline
\end{tabular}

Em que: Dap = diâmetro à altura do peito $(1,30 \mathrm{~m})$.
Apesar de grande variabilidade e irregularidade no espaçamento entre plantas, de modo geral, os povoamentos são implantados sob alta densidade populacional, na sua maioria em torno de $1,5 \mathrm{~m} \times 1,5 \mathrm{~m}$, mas que apresentam grande redução após o plantio, em decorrência da alta taxa de mortalidade (Tabela 1).

Entre os compartimentos analisados (eucalipto, sub-bosque e serapilheira), a biomassa relativa do eucalipto apresentou elevação, em relação à biomassa total do povoamento, com o aumento da idade (Tabela 2).

De modo análogo, no compartimento eucalipto, a biomassa relativa de madeira apresentou um substancial aumento com a idade do povoamento, passando de $47 \%$ aos dois anos de idade, para $74,4 \%$

TABELA 2: Biomassa dos compartimentos eucalipto, sub-bosque e serapilheira $\left(\mathrm{Mg} \mathrm{ha} \mathrm{h}^{-1}\right)$, em povoamentos de Eucalyptus spp. em propriedades rurais de Vera Cruz, RS, 2003.

TABLE 2: Eucalyptus, understory and litter biomass $\left(\mathrm{Mg} \mathrm{ha}^{-1}\right)$ in Eucalyptus spp. stands in rural properties in Vera Cruz, RS, 2003.

\begin{tabular}{|c|c|c|c|c|c|}
\hline \multirow{2}{*}{\multicolumn{2}{|c|}{$\begin{array}{l}\text { Compartimento/ } \\
\text { componente }\end{array}$}} & \multicolumn{4}{|c|}{ Idade do povoamento (anos) } \\
\hline & & \multirow{2}{*}{$\frac{2}{2,70}$} & \multirow{2}{*}{\begin{tabular}{|c|}
4 \\
3,96
\end{tabular}} & \multirow{2}{*}{$\begin{array}{c}6 \\
5,96\end{array}$} & \multirow{2}{*}{$\begin{array}{c}8 \\
6,78\end{array}$} \\
\hline \multirow{7}{*}{ 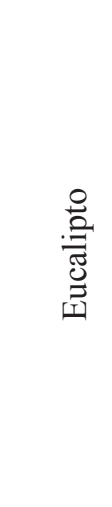 } & Folha & & & & \\
\hline & $\begin{array}{l}\text { Galho } \\
\text { vivo }\end{array}$ & 5,42 & 8,00 & 12,33 & 13,84 \\
\hline & $\begin{array}{l}\text { Galho } \\
\text { morto }\end{array}$ & 0,55 & 0,97 & - & - \\
\hline & Casca & 2,10 & 3,46 & 11,86 & 13,94 \\
\hline & Madeira & 12,56 & 22,55 & 141,58 & 173,20 \\
\hline & Raiz & 3,37 & 5,61 & 20,94 & 25,17 \\
\hline & Total & $\begin{array}{l}26,70 \\
(81,9)\end{array}$ & $\begin{array}{l}44,55 \\
(84,9)\end{array}$ & $\begin{array}{l}192,67 \\
(92,3)\end{array}$ & $\begin{array}{r}232,93 \\
(91,9)\end{array}$ \\
\hline \multirow{3}{*}{ 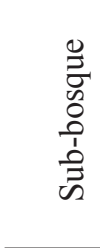 } & $\begin{array}{l}\text { Acima } \\
\text { do solo }\end{array}$ & 1,58 & 1,56 & 3,47 & 6,55 \\
\hline & Raiz & 0,31 & 0,31 & 0,90 & 1,73 \\
\hline & Total & $\begin{array}{l}1,87 \\
(5,7) \\
\end{array}$ & $\begin{array}{l}1,97 \\
(3,8) \\
\end{array}$ & $\begin{array}{l}4,37 \\
(2,1) \\
\end{array}$ & $\begin{array}{l}8,24 \\
(3,3) \\
\end{array}$ \\
\hline \multicolumn{2}{|c|}{ Serapilheira } & $\begin{array}{c}4,05 \\
(12,4)\end{array}$ & $\begin{array}{c}5,98 \\
(11,4)\end{array}$ & $\begin{array}{l}11,80 \\
(5,7)\end{array}$ & $\begin{array}{c}12,28 \\
(4,8)\end{array}$ \\
\hline \multicolumn{2}{|c|}{ Biomassa total } & 32,62 & 52,50 & 208,84 & 253,45 \\
\hline
\end{tabular}

Em que: Valores entre parênteses referem-se à contribuição percentual do respectivo compartimento em relação à biomassa total do povoamento. 
aos 8 anos (Figura 1). Se considerada a biomassa do tronco (madeira + casca), esta passou de 54,9\% aos 2 anos para $80,3 \%$ aos 8 anos de idade. A tendência de acúmulo de biomassa na madeira em função da idade das árvores indica que a colheita quando realizada em florestas jovens, antes de 6 anos de idade, acarreta perda significativa no rendimento de madeira.

Afora povoamentos extremamente jovens, a madeira do tronco é o componente das árvores que apresenta a maior biomassa relativa (REIS e BARROS, 1990).

Embora tenha havido aumento absoluto nos valores de biomassa de folha, galho vivo, galho morto, casca e raiz, a biomassa relativa desses componentes da biomassa de eucalipto apresentou redução em função da idade, sendo que galho morto, não foi encontrado em quantidade significativa nos povoamentos a partir de 6 anos de idade (Figura 1).

Os resultados obtidos, quanto à partição de biomassa em função da idade, assemelham-se aos encontrados para o gênero Eucalyptus, por Bellote (1979), Pereira et al. (1984), Bernardo (1995), Luy et al. (1997) sob diferentes condições edafoclimáticas.

A explicação para esse comportamento da distribuição de biomassa nos diferentes componentes, ao longo do desenvolvimento dos povoamentos florestais, está nas fases nutricionais das árvores (GONÇALVES et al., 2000). A primeira delas, antes do fechamento das copas e depois

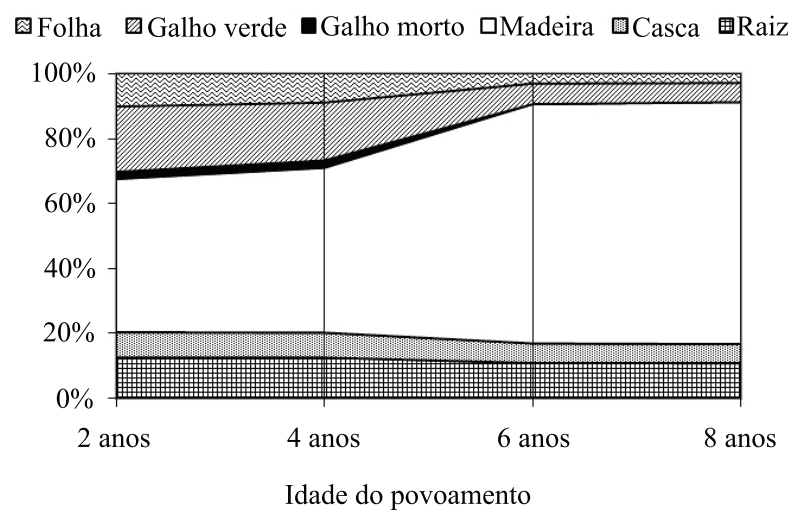

FIGURA 1: Distribuição de biomassa dos componentes das árvores nas diferentes idades em povoamentos de Eucalyptus spp. em propriedades rurais de Vera Cruz, RS, 2003.

FIGURE 1: Biomass distribution of each tree component in different ages of Eucalyptus spp. stands in rural properties in Vera Cruz, RS, 2003. de bem adaptadas ao campo, ocorre um período de intenso crescimento no qual a maior parte dos fotoassimilados sintetizados pela planta é canalizada para a formação da copa (expansão da área foliar) e sistema radicular. Nessa fase, as raízes exploram parcialmente o volume de solo e as árvores não competem entre si por fatores de crescimento (luz, água, nutrientes), sendo o seu crescimento limitado pelas suas próprias condições fisiológicas. A segunda fase se dá a partir do fechamento das copas das árvores, aí, o acúmulo de nutrientes ocorre com mais intensidade nos troncos, uma vez que a formação de copas atinge uma fase de relativa estabilidade, em razão do auto-sombreamento que impõe uma área foliar máxima limite.

Outros fatores que afetam a distribuição percentual da biomassa nos diferentes componentes das árvores, além da idade, são: a espécie, a fertilidade do solo e a densidade de plantio.

A qualidade do sítio, em termos de produtividade, pode provocar alteração na distribuição de biomassa entre os componentes da árvore em função da alocação de carbono para o sistema radicular (REIS et al., 1985; REIS et al., 1987). Reis et al. (1985), estudando o acúmulo de biomassa numa sequência de idades de Eucalyptus grandis, em duas áreas com diferentes produtividades, estimaram na área menos produtiva uma participação percentual maior do sistema radicular, apresentando uma tendência de compensar a baixa fertilidade do solo com o desenvolvimento de um sistema radicular mais extenso, capaz de acessar um maior volume de solo.

Couto et al. (1977), Leite et al. (1997), Leles et al. (1998), Assis et al. (1999) e Ladeira et al. (2001) encontraram diferença na distribuição de biomassa entre espécies e para a mesma espécie de eucalipto, em função de fatores como espaçamento de plantio e idade do povoamento.

Segundo Ladeira et al. (2001) e Leite et al. (1997), à medida que aumenta a densidade populacional, a biomassa total por unidade de área aumenta, ao passo que a produção de biomassa total por indivíduo diminui, mas com elevação da alocação de fotoassimilados no tronco.

A vegetação que se desenvolve associada à cultura do eucalipto (matocompetição) normalmente prejudica o desenvolvimento da floresta, necessitando de controle, pelo menos durante o primeiro ano após o plantio das árvores. Após essa fase, o eucalipto geralmente já está bem estabelecido e à medida que a copa se desenvolve

Ci. Fl., v. 21, n. 1, jan.-mar., 2011 
o sombreamento restringe o desenvolvimento mais nocivo da vegetação de sub-bosque. Com o aumento da idade do povoamento, vão se formando aberturas no dossel da floresta, permitindo a entrada de luz, o que novamente estimula o desenvolvimento do sub-bosque que, para as condições do estudo, foi verificado após o $6^{\circ}$ ano de idade.

Se na fase inicial, a matocompetição pode se tornar um empecilho ao estabelecimento da floresta, à medida que ela vai se desenvolvendo, a presença de sub-bosque pode ter mais reflexos positivos do que negativos. Apesar da competição por água e nutrientes, de modo geral, em longo prazo, a presença de sub-bosque atua positivamente na ciclagem de nutrientes, favorecendo a fixação de nitrogênio, enriquecendo a serapilheira, o que auxilia na sua decomposição e disponibilização de nutrientes, elevação dos teores de carbono no solo e do estoque de nutrientes para as próximas rotações.

Costa (1990) salienta a importância da heterogeneidade da comunidade vegetal que, no caso do sub-bosque de plantios florestais, pode corroborar para a manutenção dos nutrientes no sistema solo-planta. Em função das diferentes exigências nutricionais, quanto maior a heterogeneidade da comunidade vegetal, melhor será o equilíbrio dos nutrientes no ecossistema. Não obstante, o sub-bosque desempenha um aspecto conservacionista muito importante, sobretudo em áreas de topografia acidentada onde, juntamente com as árvores de eucalipto a vegetação de subbosque, funciona como uma barreira física ao escoamento superficial protegendo o solo contra a erosão, que se constitui no principal degradador da produção do ecossistema.

Em termos absolutos, tanto o sub-bosque como a serapilheira apresentaram elevação nos valores de biomassa em função do aumento da idade (Tabela 2). No entanto, em termos relativos, de modo geral, isso não ocorreu sobretudo em função da grande alocação de biomassa no compartimento eucalipto.

Os valores de serapilheira acumulada tendem a aumentar em função da idade do povoamento, até atingir certo equilíbrio quando as taxas de deposição e decomposição se equivalem.

Pereira et al. (1984), estudando Eucalyptus grandis numa sequência de idades, encontraram 1,$10 ; 2,40 ; 4,25 ; 5,66 ; 6,60 ; 7,70$ e $11,80 \mathrm{Mg} \mathrm{ha}^{-1} \mathrm{de}$ serapilheira acumulada, respectivamente, aos 1,2 , $3,4,5,6$ e 7 anos de idade.

\section{CONCLUSÕES}

Os componentes folha, galho vivo, galho morto, casca e raiz, apresentaram redução da biomassa relativa em função da idade.

A madeira apresentou aumento na biomassa relativa em função da idade.

O corte precoce, realizado antes de 6 anos de idade, implica em perda do rendimento de madeira.

\section{AGRADECIMENTOS}

Ao Sindicato da Indústria do Fumo SINDIFUMO e à Associação dos Fumicultores do Brasil - AFUBRA, pela viabilização econômica deste estudo. Aos proprietários rurais: José Hildor Hoff, Norberto Petry, Lauri Zibel e Ari Müller, que permitiram o levantamento dos dados em suas florestas. À Prefeitura municipal da cidade de Vera Cruz, pela cessão de equipamento.

\section{REFERÊNCIAS BIBLIOGRÁFICAS}

ABRAF - Associação Brasileira de Produtores de Florestas Plantadas. Anuário estatístico da ABRAF 2009 - ano base 2008. ABRAF, Brasília, 2009. 31 p. ASSIS, R. L. et al. Produção de biomassa de Eucalyptus urophylla S.T. Blake sob diferentes espaçamentos da região de cerrado de Minas Gerais. Revista Árvore, Viçosa, v. 23, n. 2, p. 151-156, abr.jun. 1999.

ATTIWILL, P. M. Nutrient cycling in a Eucalyptus oblique (L'Herit) forest. IV. Nutrient uptake and nutrition return. Australian Journal of Botany, Collingwood, v. 28, n. 2, p. 199-222, Mar/Apr. 1980.

BALLARD, R. Fertilization of plantations. In: BOWEN, G. D., NAMBIAR, E. K. S. (eds.) Nutrition of plantation forests. London: Academic Press, 1984. p. 327-360.

BALLONI, E. A. Efeitos da fertilização mineral sobre o desenvolvimento de Pinus caribaea Morelet Var. bahamensis (Griseb) Barret et Golfari em solo de cerrado do Estado de São Paulo. 1984. 110 f. Dissertação (Mestrado em Engenharia Florestal)-Escola Superior de Agricultura Luiz de Queiroz, Piracicaba, 1984.

BARROS, N. F. et al. Algumas relações soloespécie de eucalipto em suas condições naturais. In: BARROS, N. F.; NOVAIS, R. F. (eds.) Relação solo-eucalipto. Viçosa: Folha de Viçosa, 1990. cap. 
1, p. 1-24.

BELlOTE, A. F. J. Concentração, acúmulo e exportação de nutrientes pelo Eucalyptus grandis em função da idade. 1979. 192 f. Dissertação (Mestrado em Engenharia Florestal) - Escola Superior de Agricultura Luiz de Queiroz, Piracicaba, 1979.

BERNARDO, A. L. Crescimento e eficiência nutricional de Eucalyptus spp. sob diferentes espaçamentos na região de Minas Gerais. 1995. 102 p. Dissertação (Mestrado em Engenharia Florestal)-Universidade Federal de Viçosa, Viçosa, 1995.

COSTA, L. M. Manejo de solos em áreas florestais. In: BARROS, N. F.; NOVAIS, R. F. (eds.) Relação solo eucalipto. Viçosa: Ed. Folha de Viçosa, 1990. cap. 6, p. 237-302.

COUTO, L. et al. Influência do espaçamento no crescimento do Eucalyptus "urophylla" de origem híbrida, cultivado na região de Coronel Fabriciano, Minas Gerais. Revista Árvore, Viçosa, v. 1, n. 2, p. 57-71, jul./dez.1977.

CRANE, W. J. B., RAISON, R. J. Removal of phosphorus in logs when harvesting Eucalyptus delegatensis and Pinus radiata forests on short and long rotations. Australian Forestry, Yarralumla, v. 43, n. 4, p. 253-260, Oct./Dec. 1980.

GOMES, R. T. Efeito do espaçamento no crescimento e nas relações hídricas de Eucalyptus spp. na região de cerrado de Minas Gerais. 1994. 85 p. Dissertação (Mestrado em Ciência Florestal)Universidade Federal de Viçosa, Viçosa, 1994.

GONÇALVES, J. L. M. et al. Reflexos do cultivo mínimo e intensivo do solo em sua fertilidade e na nutrição das árvores. In: GONÇALVES, J. L. M.; BENEDETTI, V. (eds.) Nutrição e fertilização florestal. Piracicaba: IPEF, 2000. cap. 1. p. 1-57. GUREVITCH, J.; SCHEINER, S. M; FOX, G. A. Ecologia Vegetal. 2. ed. Porto Alegre: Artmed, 2009. 592 p.

LADEIRA, B. C. et al. Produção de biomassa de eucalipto sob três espaçamentos em uma seqüência de idade. Revista Árvore, Viçosa, v. 25, n. 1, p. 69 - 78, jan./mar. 2001.

LAL, R.; KIMBLE, J.; FOLLETT, R. F. Pedospheric processes and the carbon cycle. In: LAL, R.; KIMBLE, J.; FOLLETT, R. F.; STEWART, B. A. (eds.) Soil processes and the carbon cycle. New York: CRC Press LLC, 1998, p. 1-8.

LEITE, F. P. et al. Crescimento de Eucalyptus grandis em diferentes densidades populacionais. Revista Árvore, Viçosa, v. 21, n. 3, p. 313-321, jul./ set. 1997.

LELES, P. S. S. et al. Relações hídricas e crescimento de árvores de Eucalyptus camaldulensis e Eucalyptus pellita sob diferentes espaçamentos na região de cerrado. Revista Árvore, Viçosa, v. 22, n. 1, p. 41-50, jan./mar. 1998.

LUY, A.; GOYA, J. F.; FRANGI, J. L. Distribuición de la biomassa aérea y subterránea en plantaciones de Eucalyptus grandis de distintas edades en la región de Concordia, Entre Ríos, Argentina. In: CONGRESSO FORESTAL ARGENTINO Y LATINO-AMERICANO, 12., 1997, PosadasMissiones. Anais... Posadas-Missiones: Asociación Forestal Argentina, 1997, p. 1-10.

MCT - MINISTÉRIO DA CIÊNCIA E TECNOLOGIA. Disponível em: < http://www.mct. gov.br> Acesso em: 18 de agosto de 2005.

MORENO, J. A. Clima do Rio Grande do Sul. Porto Alegre: Secretaria da Agricultura, 1961. 31 p. NOVAIS, R. F.; BARROS, N. F.; NEVES, J. C. L. Nutrição mineral do eucalipto. In: BARROS, N. F.; NOVAIS, R. F. (eds). Relação solo eucalipto. Viçosa: Ed. Folha de Viçosa, 1990. cap. 2, p. 25-98. PEREIRA, A. R. et al. Concentração e distribuição de nutrientes em Eucalyptus grandis em função da idade, cultivado na região do cerrado. Brasil Florestal, Brasília n. 59, p. 27-37, jul./set. 1984.

REIS, M. G. F. et al. Acúmulo de biomassa em uma seqüência de idade de Eucalyptus grandis plantado no cerrado em duas áreas com diferentes produtividades. Revista Árvore, v. 9, n. 2, p. 149162, jul./dez. 1985.

REIS, M. G. F.; BARROS, N. F.; KIMMINS, J. P. Acúmulo de nutrientes em uma seqüência de idade de Eucalyptus grandis W. Hill ex Maiden plantado no cerrado, em duas áreas com diferentes produtividades, em Minas Gerais. Revista Árvore, Viçosa, v. 11, n. 1, p. 1 - 15, jan./jun. 1987.

REIS, M. G. F.; BARROS, N. F. Ciclagem de nutrientes em plantios de eucalipto. In: BARROS, N. F.; NOVAIS, R. F. (eds). Relação solo eucalipto. Viçosa: Ed. Folha de Viçosa, 1990. cap. 7, p. 265302.

REIS, G. G., REIS, M. G. F. Competição por luz, água e nutrientes em povoamentos florestais. In: SIMPÓSIO BRASILEIRO DE PESQUISA FLORESTAL, 1., 1993, Belo Horizonte. Resumos ... Viçosa: SIF/UFV, 1993, p. 161-172.

REMADE - Revista da Madeira. Eucalipto: pesquisa amplia usos, Edição especial, 2003.

STRECK, E.V. et al. Solos do Rio Grande do Sul. Porto Alegre: EMATER/RS-ASCAR, 2008. 222 p. 